\title{
The use of microsatellite markers in Neotropical studies of wild birds: a literature review
}

\author{
RENAN F. MOURA ${ }^{1, *}$, DEBORAH A. DAWSON ${ }^{2}$ and DENISE M. NOGUEIRA ${ }^{3}$ \\ ${ }^{1}$ Universidade Federal Rural do Rio de Janeiro/UFRRJ, BR 465, Km 07, 23890-000 Seropédica, RJ, Brazil \\ ${ }^{2}$ Department of Animal and Plant Sciences, University of Sheffield, Western Bank, Sheffield, South Yorkshire, S10 2TN, UK \\ ${ }^{3}$ Departamento de Genética, Instituto de Ciências Biológicas e da Saúde, Universidade Federal \\ Rural do Rio de Janeiro/UFRRJ, BR 465, Km 07, 23890-000 Seropédica, RJ, Brazil
}

Manuscript received on June 20, 2016; accepted for publication on September 16, 2016

\begin{abstract}
Despite extensive habitat fragmentation, the Neotropical region possesses $30 \%$ of the world's bird species. Microsatellites have remained one of the most popular genetic markers and have been used in ecological and conservation studies since the 1990's. We conducted a literature review comparing the number of papers published from January 1990 to July 2015 that used microsatellite markers for studies of wild birds in the Neotropical region, USA and some European countries. We assigned the articles to three categories of studies: population genetics, animal behavior/kinship analysis and the development of species-specific bird microsatellite markers. We also compared the studies in the Neotropics that used heterologous versus species-specific markers and provide a list of heterologous markers of utility in multiple birds. Despite the rich bird fauna in the Neotropics, the number of articles published represents only $5.6 \%$ of that published by the USA and selected European countries. Within the Neotropical region, Brazil possessed $60.5 \%$ of the total papers published, with the remaining $39.5 \%$ shared between five countries. We conclude that the lack of specialized laboratories and resources still represents a limit to microsatellite-based genetic studies of birds within the Neotropical region. To overcome these limitations, we suggest the use of heterologous microsatellite markers as a cost-effective and time-effective tool to assist ecological studies of wild birds.
\end{abstract}

Key words: AVES, cross-species amplification, biodiversity, ecology, molecular markers, STR.

\section{INTRODUCTION}

Microsatellites, also referred to as simple sequence repeats (SSRs), are characterized by short tandem repeats (STRs) of 1 to 6 nucleotide motifs widely spread in a random nature throughout the eukaryotic genome (Weber and May 1989, Weber 1990, Katti et al. 2001, Dakin and Avise 2004, Ellegren 2004).

\footnotetext{
Correspondence to: Denise Monnerat Nogueira

E-mail: denisemn@hotmail.com

*Current address: Programa de Pós-Graduação em Ecologia e Conservação de Recursos Naturais, Universidade Federal de Uberlândia/UFU, Av. Pará, 1720, Umuarama, 38405-320 Uberlândia, MG, Brazil
}

Mutations in microsatellite repeat regions are frequent (Goldstein and Schlötterer 1999) and the loci present in vertebrates, invertebrates and plants are therefore highly variable and characterized by high heterozygosity due to the presence of multiple alleles (Barbará et al. 2007, Tang et al. 2008). The variation found in microsatellites is normally assessed by comparing the length of the alleles as opposed to the sequence base nucleotide composition itself (Ellegren 2004) and this allele size variation is identified by PCR amplification (Primmer et al. 1996). The codominant nature and 
the fact, that, generally, these markers are located in non-coding regions where mutations possibly do not interfere in the individual's fitness, allows multiple different alleles to persist in the genome, and be transmitted to future generations (Ellegren 2004). These factors contributed to the exponential increase in the use of these markers during the 1990s and 2000s, and nowadays, they are the most popular choice for studies of population structure, kinship analysis and individual identification (Selkoe and Toonen 2006).

However, the identification of new polymorphic microsatellite loci for each species to be studied requires staff expertise, specialized laboratories and is expensive (the consumables required for sequencing and oligonucleotides for a single population/parentage study can cost more than 2,900 US dollars per species) and despite some advances, isolating and validating a microsatellite marker set remains a relatively time consuming task (Primmer et al. 1996, Dawson et al. 2013). Although it is a relatively common practice in the United States of America and many European countries, the isolation and development of such markers in the Neotropical region remains limited (Dawson et al. 1997, Gibbs et al. 1999). Seeking to overcome these limitations, the development of microsatellite primer sets has focused on methods to extend and enhance the utility of microsatellites to a wide range of species. These are called heterologous primers and their usefulness is to enable cross-species amplification (Primmer et al. 2005, Dawson et al. 2010).

In most cases, a reduction of the allelic diversity is expected when heterologous primers are used (FitzSimmons et al. 1995). This observation is, in part, due to the occurrence of variation in the flanking sequences of microsatellite loci between species, leading to base mismatches between the primer and target species and so failure of some alleles to amplify. These primer-target mismatches increase as the phylogenetic distance between the target and the source species from which the primers were designed increases (Moore et al. 1991, Schlötterer et al. 1991, Primmer et al. 1996, Barbará et al. 2007). However, recent studies in birds have identified a large number of microsatellite sequences which were sufficiently conserved between species that primer sets could be designed to perform cross-species amplification in very distant species, such as Taeniopygia guttata (zebra finch, Passeriformes order) and Gallus gallus (domestic chicken, Galliformes order), whilst displaying a high rate of polymorphism (Dawson et al. 2010, 2013).

The richness of bird species in the world is centered mainly in the Neotropical region (Neotropics). It covers the edge of the northern rain forests of Mexico $\left(20^{\circ} \mathrm{N}\right)$ up to Cape Horn $\left(57^{\circ} \mathrm{S}\right)$ in Chile, and includes all of South and Central America and the Antilles. This region comprises 3300 bird species (Haffer 1987) of the 9700 species extant in the world (Sibley and Monroe 1990). South America is very rich in bird species, yielding 2920, almost a third of all species of birds found on the planet. Peru and Colombia, although relatively small, rival Brazil in terms of bird species and this is probably because they share the species richness of the Amazon and Andean fauna (Sick 1997). According to the Brazilian Ornithological Records Committee, Brazil has the second richest bird fauna in the world, after Colombia, with 1919 species (Piacentini et al. 2015), which represents more than $50 \%$ of bird species that occur in the South American continent (Marini and Garcia 2005). The great richness of bird species in Neotropical region allied to the high rate of threat to species in diverse biomes emphasize the urgency of research focused on conservation, such as the analysis of the genetic diversity of natural populations and assessing the capacity for the maintenance of gene flow. According to Myers and collaborators (2000), 35\% of vertebrate species are contained in 25 regions of the planet, called hotspots. Seven of these 'species 
hotspots' are located in the Neotropical region (Mesoamerica, Caribbean, Western Ecuador, Tropical Andes, Brazilian Cerrado, Central Chile and Brazilian Atlantic Forest). Only $30 \%$ or less of the natural vegetation of these areas persists which means, that these regions represent threatened ecosystems.

One possible consequence of extensive habitat fragmentation is a reduction in genetic variability due to a small effective population size (Hanski and Gilpin 1997, Amos and Harwood 1998, Lowe et al. 2005). Other consequences are the genetic structuring and morphological divergence of the populations due to reduced gene flow, enhanced by the action of genetic drift, mostly in small populations, and natural selection, which favors local adaptations (Slatkin 1987, McDonald et al. 1999). However, for some bird species, genetic structuring is a feature associated with the natural behavior of the species and is not related to barriers to dispersal, neither natural nor human-created barriers, such as habitat fragmentation caused by deforestation (Francisco et al. 2007, Francisco et al. 2009).

Reliable estimates of population genetic structure are important considerations when creating conservation management plans for endangered species and protecting habitat (Balloux and LugonMoulin 2002, Moritz 1994, Paetkau 1999, Paetkau et al. 2004, Koskela et al. 2013). For this purpose, microsatellite markers represent one of the most important genetic tools. Therefore, our goal was to conduct a literature review to evaluate the number and main applications of scientific papers produced by authors from the American and European continents that used microsatellite markers in studies of avian molecular ecology. Furthermore, we present a list of published heterologous bird markers displaying high cross-species utility.

\section{MATERIALS AND METHODS}

We performed a literature review of the use of microsatellite markers for the genetic analysis of wild birds made by researchers from the American and European continents from January 1990 to July 2015 (see Supplementary Material). We selected papers involving studies of free-living wild birds that focused on population genetics, animal behavior, kinship analysis, and we also identified papers that only reported the isolation and characterization of microsatellite markers. We used a database of scientific papers - Web of Science. The search was performed by the "advanced search" option using a key sequence that included the words: "TS= (bird* AND microsatellite*) AND $\mathrm{CU}=$ (the country we wanted to verify, for example, Brazil)", with "TS" indicating the selected topic (the asterisks allow variations of these two words, like plural or compound words). The word "AND" indicates that both of the words must be present. The countries ("CU") included in the search were: Argentina, Brazil, Chile, Colombia, Costa Rica and Mexico for the Neotropical region; the United Kingdom (UK - England, Scotland, Northern Ireland and Wales), France, Germany, Spain and Sweden for the European continent; and the United States of America (USA) in North America. In the Neotropical region, we selected countries where at least one article involving the selected topics was found. We used this criteria due to the low number of papers published relating to microsatellite-based studies of birds in this region. According to the high number of published papers in Europe, we included the countries that presented at least 20 articles. We considered these countries as the most productive. We also included the USA due to the large number of articles published by the researchers from this country.

We emphasize that the search was based on the address provided for the first author. This means that if the institution of the first author is listed as Germany, we considered it as a German paper. In cases where the first author was from an institution of a country not included in our analysis, we used the institute of the second author. When an author presented multiple addresses, we choose the ad- 
dress provided for correspondence. If this information were not clear or available, we used the first cited address. We considered these first or second authors as principal investigators (PIs). Using this approach, we intend to standardize and organize the papers into their respective countries, as many studies included authors with multiple addresses.

The number of papers published by PIs employed in the Neotropical region was compared to the number published in the USA and selected European countries. We also recorded the main application of the microsatellite markers by Neotropical PIs and whether they used speciesspecific or heterologous primer sets. Finally, we provided a list of heterologous microsatellite markers of high cross-species utility in multiple passerine and non-passerine bird species.

\section{RESULTS}

We found 774 scientific papers published between January 1990 and July 2015 that used microsatellite markers for bird studies where the PI was based in the American or European continents (Fig. 1 ), according to the selected topics. The highest number of bird microsatellite studies was published

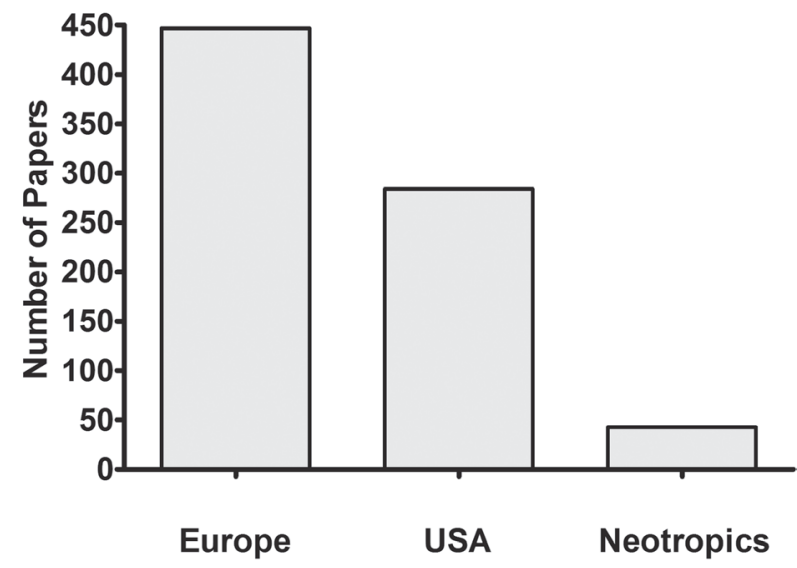

Figure 1 - Total number of scientific articles published between January 1990 and July 2015 by authors from selected European countries, USA and from six countries of the Neotropical region that used microsatellite markers for studies of birds, involving population genetics, behavior/kinship and/ or the characterization of microsatellites markers. by European PIs, representing 447 papers in total. In second place with 284 publications were those papers with a PI based in the USA. Much lower in the rankings, with a total of 43 scientific papers were those publications where the PI was based in the Neotropical region (see Supplementary Material). For this region, in descending order, the main productive countries were: Brazil (26), Argentina (6), Mexico (4), Chile (3), Costa Rica (3) and Colombia (1) (Fig. 2). Among the European countries, we found the following number (in brackets) of published papers for each country: the UK (194), Germany (79), Sweden (74), Spain (54) and France (46). Brazil stands out from the other Neotropical countries with $60.5 \%$ of the total papers found for this region, although the publications by Neotropical countries represented only $5.6 \%$ of all papers found, compared to $36.7 \%$ from the USA, and $57.7 \%$ from European countries.

Regarding the main application of the microsatellite markers for studies of birds in the Neotropical region, from the 43 articles: $55.8 \%$ [Brazil (12), Argentina (4), Mexico (3), Chile (2), Costa Rica (2) and Colombia (1)] involved studies of population genetics, whereas $30.2 \%$ [Brazil

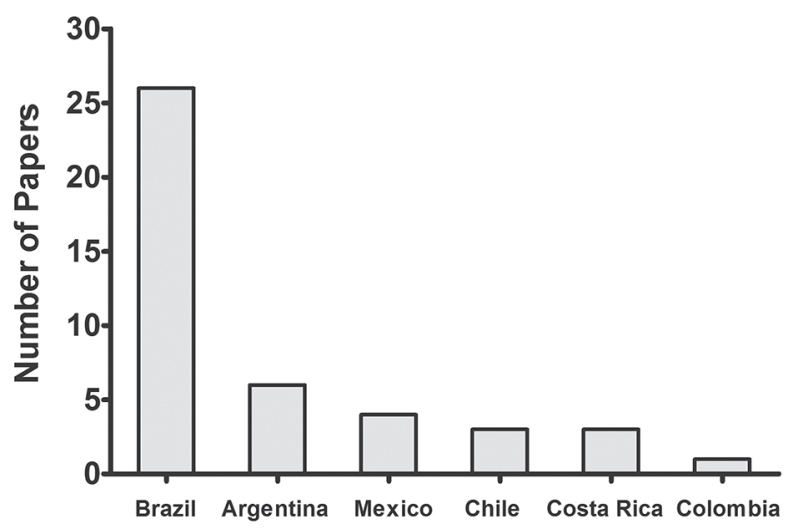

Figure 2 - Total number of scientific articles published between January 1990 and July 2015 by authors from the Neotropical region that used microsatellite markers for studies of birds, involving population genetics, behavior/kinship and/or the characterization of microsatellites markers. 
(9), Argentina (2), Costa Rica (1) and Mexico (1)] focused on behavior and/or kinship studies and 14\% of the articles [Brazil (5) and Chile (1)] reported the isolation and characterization of speciesspecific microsatellite loci (Table I). According to our research, there are no microsatellite studies of birds published by authors from other Neotropical countries than those we listed above. The same pattern was observed for the publications from the USA and Europe. From the 284 articles authored by North American PIs, 65.5\% (186) involved population genetic studies, $20.1 \%$ were related to behavior/kinship (57) and $14.4 \%$ (41) described the isolation and characterization of microsatellite loci. In Europe, from the 447 papers, we found $57.9 \%$ of the articles (90 from the UK, 58 from Sweden, 42 from Spain, 36 from Germany, and 33 from France) were studies of population genetics, $26.6 \%$ (30 from Germany, 60 from the UK, 14 from Sweden, nine from France and six from Spain) involved behavior and/or kinship studies and 15.5\% (44 from the UK, 13 from Germany, six from Spain, four from France and two from Sweden) concerned the isolation and characterization of microsatellite loci (Table I).

Regarding the use of heterologous microsatellite markers for the study of birds by PIs based in the Neotropical region, we found 14 papers, most of them published between the years 2000 and 2015 (eight from Brazil, three from Argentina and one from each of Chile, Colombia and Costa Rica). This number is slightly smaller than that found for studies that used only species-specific microsatellite markers, comprising 17 (eight from Brazil, four from Mexico, two from Chile, two from Costa Rica and one from Argentina). In seven papers (five from Brazil and two from Argentina), the studies were conducted using both types of markers, species-specific and heterologous. Finally, five articles from Brazil and one from Chile described only the isolation and characterization of microsatellites and did not use them for any other purpose in the same article (e. g. population/parentage), thus we did not include them in the total number of articles

TABLE I

Total number of scientific articles published by authors from the Neotropical Region, USA and most productive European countries between January 1990 and July 2015 that used microsatellite markers for studies of birds, involving population genetics, behavior/kinship and/or the characterization of microsatellites. * Neotropical countries: BR= Brazil, AR= Argentina, $\mathrm{ME}=$ Mexico, $\mathbf{C H}=\mathbf{C h i l e}, \mathbf{C R}=$ Costa Rica, $\mathbf{C O}=$ Colombia. $* *$ United Kingdom (UK) countries: England, Scotland, Wales and Northern Ireland.

\begin{tabular}{|c|c|c|c|c|c|c|c|c|c|c|c|c|}
\hline & \multicolumn{6}{|c|}{ Neotropical countries* } & \multirow[b]{2}{*}{ USA } & \multicolumn{5}{|c|}{ European countries } \\
\hline & $\mathrm{BR}$ & AR & $\mathrm{ME}$ & $\mathrm{CH}$ & $\mathrm{CR}$ & $\mathrm{CO}$ & & $\mathrm{UK}^{* *}$ & Germany & Sweden & Spain & France \\
\hline Population Genetics & 12 & 4 & 3 & 2 & 2 & 1 & 186 & 90 & 36 & 58 & 42 & 33 \\
\hline Behavior and/ or Kinship & 9 & 2 & 1 & 0 & 1 & 0 & 57 & 60 & 30 & 14 & 6 & 9 \\
\hline $\begin{array}{l}\text { Isolation and Characterization } \\
\text { of Microsatellites }\end{array}$ & 5 & 0 & 0 & 1 & 0 & 0 & 41 & 44 & 13 & 2 & 6 & 4 \\
\hline Total Number of Articles & 26 & 6 & 4 & 3 & 3 & 1 & 284 & 194 & 79 & 74 & 54 & 46 \\
\hline
\end{tabular}

TABLE II

Number of scientific articles published between January 1990 and July 2015 by authors from six countries of the Neotropical Region that used heterologous, species-specific or both types of microsatellites markers for studies of wild birds, concerning population genetic studies or behavior/kinship*.

\begin{tabular}{cccccccc}
\hline & Brazil & Argentina & Mexico & Chile & Costa Rica & Colombia & Total of Articles \\
\hline Heterologous Markers & 8 & 3 & 0 & 1 & 1 & 1 & 14 \\
\hline Species-specific Markers & 8 & 1 & 4 & 2 & 2 & 0 & 17 \\
\hline Both Types of Marker & 5 & 2 & 0 & 0 & 0 & 0 & 7 \\
\hline Total Number of Articles & 21 & 6 & 4 & 3 & 3 & 1 & 38
\end{tabular}

*We did not include articles that only described the isolation and characterization of microsatellite markers. 
from these countries (Table II). According to the data obtained we identified and list some microsatellite markers with high rates of polymorphism in multiple different bird species that are suitable for genetic studies of a wide range of passerines and non-passerines (Table III).

\section{DISCUSSION}

Our results showed a great disparity regarding the number of papers published by PIs based in the Neotropical region involving bird microsatellite markers against the number published by PIs based in Europe and the USA between January 1990 and July 2015. Nevertheless, Brazil has an important position in the Neotropical region with 26 papers published by Brazilian PIs in this period representing $60.5 \%$ of the total number published, four times more than the second most productive country, Argentina.

Regarding the number of papers published per country, the USA was the most productive, with almost $46.4 \%$ more papers than produced by the UK which occupies second place. Despite the rich avifauna in Colombia, we found only one paper published by a PI from this country. For another country possessing an extremely rich avifauna, Peru, no papers were published by any Peruvian PIs over this period.

TABLE III

Ranking of the most useful microsatellites markers for genetic studies of passerines and non-passerines, selected according to their cross-utility in multiple species.

Recommended order to test markers to find those useful for genetic

Marker name

Reference

Notes studies in passerines

(a) Passerines $\uparrow$

Engineered EST markers: both primers are a 100\% match to chicken and zebra finch, possessed no degenerate bases, with a repeat in zebra finch. Test all markers except TG01-092 and TG09-014 *

Engineered markers: both primers were a $100 \%$ match to chicken and zebra finch, possessed 0-3 degenerate bases per set and included a repeat in both chicken and zebra finch *

9 loci isolated from various passerines and tested

LOX1, Phtr2, ZL04,

Slate et al. 2007 (see Klein

$4 \quad$ Tgu6 $(=$ Pte24)

GG-C25, TguEST09, 10, 13, 16,

5 $32,46,48,62,69,75$ et al. 2009, Martín-Gálvez et al. 2009, Simeoni et al. 2009, Martín-Gálvez et al. 2014) 81,85

Ppi2, Pdo 45, Mjg1, Galbusera et al. 2000, (see Mcy4 (Мсун4), also Martín-Gálvez et al.

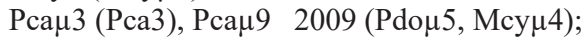
(Pca9), Pat14 (PAT Simeoni et al. 2007 (Ppi2, MP 2-14), Pat43 Pca3, LOX1, plus Ase18, (PAT MP 2-43), Ls1, Man13-Gga), Simeoni et al. Ls2, Phtr3. Gf4, Gf6, 2009, (PAT MP 2-14 and PAT Z104, LOX1.
Zebra finch EST locus known to be of utility in distantly related species including multiple passerines, an owl and a roller.

Zebra finch EST loci, Amplified in at least 7 of 8 species tested ( 7 passerines and an owl) and polymorphic in at least 5 of 8 species.

Loci isolated from various passerines and display cross-species utility in multiple species. 
TABLE III (continuation)

\begin{tabular}{|c|c|c|c|}
\hline $\begin{array}{l}\text { Recommended order to } \\
\text { test markers to find those } \\
\text { useful for genetic studies } \\
\text { in non-passerines }\end{array}$ & Marker name & Reference & Notes \\
\hline \multicolumn{4}{|c|}{ (b) Non-passerines $\uparrow$} \\
\hline 1 & $\begin{array}{l}\text { CAM-06, CAM-13, } \\
\text { CAM-17, CAM-18, } \\
\text { CAM-20 and CAM- } \\
24 \text { (CAM set } 1, n=6 \\
\text { markers) }\end{array}$ & Dawson et al. 2013 & $\begin{array}{l}\text { Engineered markers: both primers are a } 100 \% \\
\text { match to chicken and zebra finch, possessed no } \\
\text { degenerate bases and included a repeat in both } \\
\text { chicken and zebra finch. }\end{array}$ \\
\hline 2 & TG markers $(n=33)$ & Dawson et al. 2010 & $\begin{array}{l}\text { Engineered EST markers: both primers are a } 100 \% \\
\text { match to chicken and zebra finch, possessed no } \\
\text { degenerate bases, with a repeat in zebra finch. Test } \\
\text { all except TG01-092 and TG09-014* }\end{array}$ \\
\hline 3 & $\begin{array}{l}\text { Bb111-TG, HvoB1- } \\
\text { TGG and TG04-061 }\end{array}$ & $\begin{array}{l}\text { Klein et al. 2009, Martín- } \\
\text { Gálvez et al. } 2014\end{array}$ & $\begin{array}{l}\text { Utility in distantly related species including owls, } \\
\text { eagle and roller. Homology to passerines and } \\
\text { Galliformes. }\end{array}$ \\
\hline 4 & Tgu6 (=Pte24) & $\begin{array}{l}\text { Slate et al. } 2007 \text { (see Klein } \\
\text { et al. 2009, Martín-Gálvez et } \\
\text { al. 2009, Simeoni et al. 2009, } \\
\text { Martín-Gálvez et al. 2014) }\end{array}$ & $\begin{array}{l}\text { Zebra finch EST locus known to be of utility in } \\
\text { many distantly related species (including owl, } \\
\text { multiple passerines and roller). }\end{array}$ \\
\hline 5 & $\begin{array}{l}\text { Rest of the CAM } \\
\text { markers }(n=18)\end{array}$ & Dawson et al. 2013 & $\begin{array}{l}\text { Engineered markers: both primers were a } 100 \% \\
\text { match to chicken and zebra finch, possessed 1-3 } \\
\text { degenerate bases per primer set and included a } \\
\text { repeat in both chicken and zebra finch* }\end{array}$ \\
\hline 6 & $\begin{array}{l}\text { BmaTATC317, } \\
\text { Mopl 6, 15, 21, } \\
\text { 26, LarsZAP26/ } \\
\text { K32, BmTATC403, } \\
\text { Calex-01, Calex-05, } \\
\text { SNIPE B2, Rbg } 18\end{array}$ & Küpper et al. 2008 & $\begin{array}{l}\text { Markers for shorebirds: markers that successfully } \\
\text { amplified and showed polymorphism in at least } \\
2 \text { of the } 3 \text { species tested (amplification success } \\
>50 \% \text { ). }\end{array}$ \\
\hline
\end{tabular}

Studies involving microsatellite markers require specialized laboratories and equipment (Primmer et al. 1996, Dawson et al. 2013), so it is likely that the small number of such laboratories in the Neotropical region has limited the number of scientific publications related to the use of microsatellites (Dawson et al. 1997, Gibbs et al. 1999). Furthermore, it is possible that authors from the Neotropical region produce their papers in collaboration with USA and European researchers, due to the improved laboratory infrastructure and greater governmental incentive to support science in these regions. Of the 43 papers published from the Neotropical region, 11 involved the collaboration of North American authors and 13 publications involved at least one author from the following European countries: Austria, Germany, Hungary, Sweden or the UK. Of the 26 papers published by Brazilian PIs, 11 involved only Brazilian researchers and seven were produced in collaboration of either UK or/and USA researchers. Interestingly, we found that only two papers involved collaboration between researchers from different countries in the Neotropical region. 
However, we have to consider that some countries have specialized centers for the development and application of molecular tools, such as the microsatellite markers. Therefore, the lack of studies using microsatellites, especially in the Neotropical region, can also be a result of more distant connections to those who are experts in the field. For example, from the 194 UK papers, 45 (23.2\%) had the collaboration of one researcher, Deborah Dawson (see Supplementary Material *). In Brazil, the most productive country from the Neotropical region, three researchers (Silvia Del Lama, Carolina Muñoz and Mercival Francisco) were involved in 17 (65.4\%) of the 26 published papers (see Supplementary Material**). That means that few specialized laboratories account for the great majority of the papers published in in Brazil. So, in addition to the need for funding to equip laboratories with expensive sequencers, knowledge transfer from the experts is essential to promote research development within a country.

Of the 774 papers, we found that most of them $469(60.6 \%)$ were related to studies of population genetics. This is not surprising, since the knowledge regarding the population genetics of birds currently represents one of the most important sources of data considered in design strategies for the management and conservation of endangered species (Balloux and Lugon-Moulin 2002, Moritz 1994, Paetkau 1999, Paetkau et al. 2004, McMahon et al. 2014). Studies of behavior and/or kinship were the second most commonly identified subject, comprising 189 papers $(24.4 \%)$. We found only 116 papers $(15 \%)$ related to the isolation and characterization of microsatellites, which is also expected, considering that the development of polymorphic loci requires specialist expertise and equipment and can be a laborious (and so expensive) task.

The isolation and characterization of microsatellite markers for each new species is a slow and relatively costly process, which hinders their development (Primmer et al. 1996, Selkoe and
Toonen 2006, Dawson et al. 2010, 2013). The cost of primers that are fluorescently labeled is five to ten times higher than the cost of the synthesis of the unlabeled ones (Hayden et al. 2008). Additionally, from the total number of microsatellite loci isolated from a single species, only a proportion will be of utility (Barbará et al. 2007, Dawson et al. 2013). For this reason, studies have been conducted for various taxa including birds with the purpose of identifying primer sets which enable cross-amplification in different species, whilst maintaining a high degree of polymorphism, which would then dispense with the necessity for the development of new markers specifically for each species (Primmer et al. 2005, Dawson et al. 2010, Jan et al. 2012, Butler et al. 2014, Jumpa et al. 2015). Heterologous primers amplify more strongly and display a higher degree of polymorphism when used to analyze species closely related to that species from which the primer was originally developed (FitzSimmons et al. 1995, Primmer et al. 1996, Küpper et al. 2008, Dawson et al. 2010, 2013).

Considering the total number of papers published, we conclude that the use of heterologous markers in the Neotropical region is frequent. If we analyze the papers that used exclusively heterologous markers and those that used the two classes of markers (heterologous and specific), we found that, of the 43 papers published in the Neotropical region, 21 (48.8\%) used heterologous markers. Brazilian PIs published eight papers using exclusively heterologous markers, and five using heterologous and specific markers, 13 papers in total. This suggests that the use of heterologous markers is a viable option for ecological studies of birds.

The application of cross-species heterologous microsatellite markers in birds allows the study of individual traits of a species. Additionally, these markers can be used as a powerful tool, providing useful information that cannot be obtained using species-specific microsatellite markers, such as 
cross-species comparisons without ascertainment bias and for studies of karyotype and genome evolution (Primmer et al. 1996, Dawson et al. 2013).

Regarding the high number of bird species in the Neotropical region ( $n=3300$; Haffer 1987), the isolation and characterization of new microsatellite markers independently from each species would be an ineffective task due to its high cost and time (taking weeks-months per species; Dawson et al. 2010).

We consider that the identification and application of heterologous microsatellite markers obtained from Neotropical bird species will encourage more studies in this field, enabling and hastening new scientific discoveries in this region and improving our knowledge of Neotropical species.

\section{ACKNOWLEDGMENTS}

We are grateful for the suggestions provided by two anonymous referees that improved the manuscript and for the funding of the scholarship provided to RFM by Fundação de Amparo à Pesquisa do Estado do Rio de Janeiro (FAPERJ).

\section{REFERENCES}

AMOS W AND HARWOOD J. 1998. Factors affecting levels of genetic diversity in natural populations. Philos T Roy Soc B 353: 177-186.

BALLOUX F AND LUGON-MOULIN N. 2002. The estimation of population differentiation with microsatellite markers. Mol Ecol 11: 155-165.

BARBARÁ T, PALMA-SILVA C, PAGGI GM, BERED F, FAY MF AND LEXER C. 2007. Cross-species transfer of nuclear microsatellite markers: potential and limitations. Mol Ecol 16: 3759-3767.

BUTLER AI, SILETTI K, OXLEY PR AND KRONAUER DJ. 2014. Conserved Microsatellites in Ants Enable Population Genetic and Colony Pedigree Studies across a Wide Range of Species. Plos One 9: e107334.

DAKIN EE AND AVISE JC. 2004. Microsatellite null alleles in parentage analysis. Heredity 93: 504-509.

DAWSON DA et al. 2010. New methods to identify conserved microsatellite loci and develop primer sets of high crossspecies utility as demonstrated for birds. Mol Ecol Resour 10: 475-494.
DAWSON DA et al. 2013. High-utility conserved avian microsatellite markers enable parentage and population studies across a wide range of species. BMC Genomics 14: 176.

DAWSON RJ, GIBBS HL, HOBSON KAAND YEZERINAC SM. 1997. Isolation of microsatellite DNA markers from a passerine bird, Dendroica petechia (the yellow warbler), and their use in population studies. Heredity 79: 506-514.

ELLEGREN H. 2004. Microsatellites: simple sequences with complex evolution. Nat Rev Genet 5: 435-445.

FITZSIMMONS NN, MORITZ C AND MOORE SS. 1995. Conservation and dynamics of microsatellite loci over 300 million years of marine turtle evolution. Mol Biol Evol 12: 432-440.

FRANCISCO MR, GIBBS HL AND GALETTI JUNIOR PM. 2009. Patterns of individual relatedness at blue manakin (Chiroxiphia caudata) leks. The Auk 126: 47-53.

FRANCISCO MR, GIBBS HL, GALETTI M, LUNARDI VO AND GALETTI JUNIOR PM. 2007. Genetic structure in a tropical lek-breeding bird, the blue manakin (Chiroxiphia caudata) in the Brazilian Atlantic Forest. Mol Ecol 16: 4908-4918.

GALBUSERA P, VAN DONGEN S AND MATTHYSEN E. 2000. Cross-species amplification of microsatellite primers in passerine birds. Conserv Genet 1: 163-168.

GIBBS HL, TABAK LM AND HOBSON K. 1999. Characterization of microsatellite DNA loci for a Neotropical migrant songbird, the Swainson's thrush (Catharus ustulatus). Mol Ecol 8: 1551-1561.

GOLDSTEIN DB AND SCHLÖTTERER C. 1999. Microsatellites: Evolution and Application. Oxford Univ Press, New York.

HAFFER J. 1987. Quaternary history of Tropical America. In WHITMORE TC AND PRANCE GT (Eds), Biogeography and Quaternary History in Tropical America. Clarendon Press, Oxford, p. 1-18.

HANSKI I AND GILPIN ME. 1997. Metapopulation biology: ecology, genetics, and evolution. Acad Press 1: 512.

HAYDEN MJ, NGUYEN TM, WATERMAN A AND CHALMERS KJ. 2008. Multiplex ready PCR: a new method for multiplexed SSR and SNP genotyping. BMC Genomics 9: 80.

JAN C, DAWSON DA, ALTRINGHAM JD, BURKE T AND BUTLIN R. 2012. Development of conserved microsatellite markers of high cross-species utility in bat species (Vespertilionidae, Chiroptera, Mammalia). Mol Ecol Resour 12: 532-548.

JUMPA S, DAWSON DA, HORSBURGH GJ AND WALTON C. 2015. Conserved microsatellite markers of high crossspecies utility for flying, ground and tree squirrels. Conserv Genet Resour 7: 599-603.

KARAISKOU N, BUGGIOTTI L, LEDER E AND PRIMMER CR. 2008. High degree of transferability of 86 newly developed zebra finch EST-linked microsatellite markers in 8 bird species. J Hered 99: 688-693. 
KATTI MV, RANJEKAR PK AND GUPTA VS. 2001. Differential distribution of simple sequence repeats in eukaryotic genome sequences. Mol Biol Evol 18: 1161-1167.

KLEIN A, HORSBURGH GJ, KÜPPER C, MAJOR A, LEE PL, HOFFMANN G, MÁTICS R AND DAWSON DA. 2009. Microsatellite markers characterized in the barn owl (Tyto alba) and of high utility in other owls (Strigiformes: AVES). Mol Ecol Resour 9: 1512-1519.

KOSKELA J et al. 2013. Translating conservation genetics into management: Pan-European minimum requirements for dynamic conservation units of forest tree genetic diversity. Biol Cons 157: 39-49.

KÜPPER C, BURKE T, SZÉKELY T AND DAWSON DA. 2008. Enhanced cross-species utility of conserved microsatellite markers in shorebirds. BMC Genomics 9: 1-20.

LOWE AJ, BOSHIER D, WARD M, BACLES CF AND NAVARRO C. 2005. Genetic resource impacts of habitat loss and degradation; reconciling empirical evidence and predicted theory for Neotropical trees. Heredity 95: 255-273.

MARINI MA AND GARCIA FI. 2005. Conservação de aves no Brasil [Bird Conservation in Brazil]. Megadiversidade 1: $95-102$.

MARTÍN-GÁLVEZ D, DAWSON DA, HORBURGH GJ AND BURKE T. 2009. Isolation, characterization and chromosome locations of polymorphic black-billed magpie Pica pica (Corvidae, AVES) microsatellite loci. Mol Ecol Resour 9: 1506-1512.

MARTÍN-GÁLVEZ D, MOLINA-MORALES M, DAWSON DA, PAREJO D, MARTÍNEZ JG AND AVILÉS JM. 2014. Characterization of 28 microsatellite loci in the European roller Coracias garrulus (Coracidae, AVES). Eur J Wildlife Res 60: 843-850.

MCDONALD DB, POTTS WK, FITZPATRICK JW AND WOOLFENDEN GE. 1999. Contrasting genetic structures in sister species of North American scrub-jays. P Roy Soc Lond B Bio 266: 1117-1125.

MCMAHON BJ, TEELING EC AND HÖGLUND J. 2014. How and why should we implement genomics into conservation? Evol Appl 9: 999-1007.

MOORE SS, SARGEANT LL, KING TJ, MATTICK JS, GEORGES M AND HETZEL DJ. 1991. The conservation of dinucleotide microsatellites among mammalian genomes allows the use of heterologous PCR primer pairs in closely related species. Genomics 10: 654-660.

MORITZ C. 1994. Defining evolutionary significant units for conservation. Trends Ecol Evol 9: 373-375.

MYERS N, MITTERMEIER RA, MITTERMEIER CG, DA FONSECA GA AND KENT J. 2000. Biodiversity hotspots for conservation priorities. Nature 403: 853-858.

PAETKAU D, SLADE R, BURDENS M AND ESTOUP A. 2004. Genetic assignment methods for the direct, real time estimation of migration rate: a simulation-based exploration of accuracy and power. Mol Ecol 13: 55-65.

PAETKAU D. 1999. Using genetics to identify intraspecific conservation units: a critique of current methods. Conserv Biol 13: 1507-1509.
PIACENTINI et al. 2015. Annotated Checklist of the Birds of Brazil by the Brazilian Ornithological Records Committee/ Lista Comentada das Aves do Brasil pelo Comitê Brasileiro de Registros Ornitológicos. Braz Journal of Ornithology 23: 91-298.

PRIMMER CR, MØLLER AP AND ELLEGREN H. 1996. A wide-range survey of cross-species microsatellite amplification in birds. Mol Ecol 5: 365-378.

PRIMMER CR, PAINTER JN, KOSKINEN MT, PALO JU AND MERILÄ J. 2005. Factors affecting avian cross-species microsatellite amplification. J Avian Biol 36: 348-360.

SCHLÖTTERER C, AMOS W AND TAUTZ D. 1991. Conservation of polymorphic simple sequence loci in cetacean species. Nature 354: 63-65.

SELKOE KA AND TOONEN RJ. 2006. Microsatellites for ecologists: a practical guide to using and evaluating microsatellite markers. Ecol Lett 9: 615-629.

SIBLEY CG AND MONROE BL. 1990. Distribution and Taxonomy of Birds of the World. Yale University Press, New Haven, Connecticut.

SICK H. 1997. Ornitologia Brasileira. Editora Nova Fronteira, Rio de Janeiro.

SIMEONI M, DAWSON DA, GENTLE L, COIFFAIT L, WOLFF K, EVANS KL, GASTON K AND HATCHWELL BJ. 2009. Characterization of 38 microsatellite loci in the blackbird Turdus merula (Turdidae, AVES). Mol Ecol Resour 9: 1520-1526.

SIMEONI M, DAWSON DA, ROSS DJ, CHALINE N, BURKE T AND HATCHWELL BJ. 2007. Characterisation of 20 microsatelite loci in the long-tailed tit Aegithalos caudatus (Aegithalidae, AVES). Mol Ecol Notes 7: 13191322.

SLATE J, HALE MC AND BIRKHEAD TR. 2007. Simple sequence repeats in zebra finch (Taeniopygia guttata) expressed sequence tags: A new resource for evolutionary genetic studies of passerines. BMC Genomics 8: 52.

SLATKIN ME. 1987. Gene flow and the geographic structure of natural populations. Science 236: 787-792.

TANG J, BALDWIN SJ, JACOBS JM, VAN DER LINDEN CG, VOORRIPS RE, LEUNISSEN JA, VAN ECK H AND VOSMAN B. 2008 Large-scale identification of polymorphic microsatellites using an in silico approach. BMC Bioinformatics 9: 374.

WEBER JL AND MAY PE. 1989. Abundant class of human DNA polymorphisms which can be typed using the polymerase chain reaction. Am J Hum Genet 44: 388-396.

WEBER JL. 1990. Informativeness of human (dC-dA)n.(dGdT)n polymorphisms. Genomics 7: 524-530.

\section{SUPPLEMENTARY MATERIAL}

Publications identified from the Web of Science database using the search terms "bird(s)" and "microsatellite(s)" between the time period January 1990 to July 2015. 